\title{
Numerical Simulation of the Volumetric Strain Distribution of a Protected Coal Seam
}

\author{
Hengyi Jia ${ }^{1,2}$ \\ ${ }^{1}$ China Coal Research Institute, Beijing 100013, China \\ ${ }^{2}$ State Key Lab of Coal Resources High Efficient Mining and Clean Utilization, Beijing 100013, China \\ Correspondence should be addressed to Hengyi Jia; jiahengyi2@163.com
}

Received 20 May 2021; Accepted 24 July 2021; Published 13 August 2021

Academic Editor: Feng Du

Copyright (C) 2021 Hengyi Jia. This is an open access article distributed under the Creative Commons Attribution License, which permits unrestricted use, distribution, and reproduction in any medium, provided the original work is properly cited.

\begin{abstract}
To investigate the deformation characteristics of protected coal seams, the numerical simulation of the mining of an upper protective coal seam was carried out in the present study. Based on the basic definition of strain, a method for the extraction of the strain data of the protected coal seam was proposed, and the strain distribution characteristics were obtained. It was found that the $x$-direction strain is mainly distributed near the coal pillars on both sides and inside the goaf, the $y$-direction strain is mainly distributed at the working face, the initial mining line, and inside the goaf, and the $z$-direction strain is mainly distributed at the working face, the initial mining line, the coal pillars on both sides, and inside the goaf. The distribution characteristics and the value of volumetric strain were found to be basically consistent with the $z$-direction strain. As the working face advances, the protected coal seam undergoes compression and damage expansion in turn. The turning point between compression and damage expansion is approximately $15 \mathrm{~m}$ in front of the working face. The variation law of gas drainage in the boreholes of the protected coal seam is closely related to the distribution characteristics of volumetric strain. The results of this research are of great significance for the comprehensive investigation of the effects of pressure relief and the permeability enhancement of protective coal seam mining.
\end{abstract}

\section{Introduction}

Coal and gas outburst accidents have long caused substantial casualties and property losses to coal enterprises in China $[1$, $2]$. With the increase of the mining depth, both the in situ stress and gas pressure increase, and the risk of coal and gas outburst is further enhanced $[3,4]$. Both theoretical research and production practice demonstrate that the mining of protective coal seams can significantly reduce the in situ stress, expand cracks, discharge gas, and ultimately eliminate the outburst risk of protected coal seams [5-9].

The elimination of the outburst risk of protected coal seams depends on the degree of pressure relief after mining. Scholars have carried out extensive research on the deformation laws of protected coal seams from the perspectives of the relative distance between protective and protected coal seams $[10,11]$, double protective coal seam mining [12], the mining depth [13], and the impacts of protective coal seam mining on the roadways of protected coal seams [14]. However, while these studies investigated the deformation of protected coal seams in the vertical direction, the deformation of protected coal seams should be reflected in three directions (the vertical, mining, and tilt directions). Shi and Liu [15] obtained the deformation laws of protected coal seams in both the vertical and mining directions based on the theory of rock fracture and damage, they did not obtain the deformation law along the tilt direction. He et al. [16] proposed a "four fixed point enclosed area" analysis method for the deformation of protected coal seams based on similar simulation experiments and obtained the volumetric strain distribution characteristics. However, it is time-consuming, laborious, and inconvenient to change the simulation conditions to carry out similar simulation experiments. In contrast, in the numerical simulation method, the simulation conditions can easily be changed by modifying the model parameters. Therefore, obtaining the distribution characteristics of the volumetric 


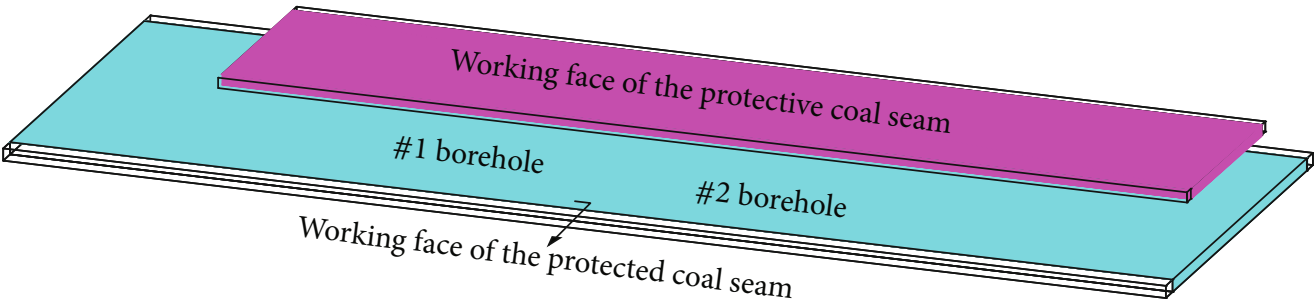

FIgURE 1: Working faces layouts.

strain via numerical simulation is important for the comprehensive investigation of protected coal seam deformation.

In this research, FLAC3D numerical simulation software was employed to study the pressure relief effect of a protected coal seam. According to the definition of strain, a method for extracting the strain data of the protected coal seam was proposed, and the strain distribution characteristics were obtained.

\section{Numerical Simulation of Protective Coal Seam Mining}

2.1. General Situation of the Coal Mine under Study. The Zhongxing coal mine is located in Shanxi Province, China. The main coal seam of the coal mine is the \#2 coal seam, which has low permeability and a severe risk of coal and gas outburst. The locally mineable \#02 coal seam is located about $10 \mathrm{~m}$ above the \#2 coal seam and has a lower risk of outburst and a reduced gas content as compared to the \#2 coal seam. To eliminate the outburst risk of the \#2 coal seam, the \#02 coal seam was mined first as an upper protective coal seam. Because the \#02 coal seam is locally mineable, the size of its working face is less than that of the protected coal seam. The sizes of the working faces of the protective and protected coal seam are, respectively, $1160 \times 75 \mathrm{~m}$ and $1595 \times 190 \mathrm{~m}$ (length $\times$ width). The layouts of the working faces are presented in Figure 1, and their basic parameters are reported in Table 1.

2.2. Establishment of the Numerical Model. Based on the strata conditions of the Zhongxing coal mine, the numerical model shown in Figure 2 was established by FLAC3D numerical simulation software. The strata conditions and mechanical parameters of the coal mine are reported in Table 2. Mining a coal seam will cause the deformation of the rock mass and a reduction in rock strength. Thus, the rock mass can be regarded as elastic-plastic material that exhibits strain-softening characteristics after it is damaged [17]. Therefore, the Mohr-Coulomb strain-softening model was selected, and the tilt angle of the rock strata in the model was set to zero for simplicity.

According to the stress condition of the Zhongxing coal mine, compressive stress of $20 \mathrm{MPa}$ was imposed at the top of the model, and a fixed boundary was imposed at the bottom of the model. The other sides of the model were set as rolling boundaries with an imposed stress of $20 \mathrm{MPa}$. The length, width, and height of the model were, respectively, 300,300 , and $131 \mathrm{~m}$. The mining length of the working face
TABle 1: Basic parameters of the coal seams.

\begin{tabular}{lcc}
\hline Parameter & $\begin{array}{c}\text { Protective coal } \\
\text { seam }\end{array}$ & $\begin{array}{c}\text { Protected coal } \\
\text { seam }\end{array}$ \\
\hline $\begin{array}{l}\text { Thickness of the coal } \\
\text { seam }\end{array}$ & $0.51 \mathrm{~m}$ (in average) & $2 \mathrm{~m}$ (in average) \\
$\begin{array}{l}\text { Tilt angle of the coal } \\
\text { seam }\end{array}$ & $7^{\circ}$ (in average) & $7^{\circ}$ (in average) \\
Original gas pressure & - & $0.82 \mathrm{MPa}$ \\
Original gas content & $3.37 \mathrm{~m}^{3} / \mathrm{t}$ & $10.4 \mathrm{~m}^{3} / \mathrm{t}$ \\
\hline
\end{tabular}
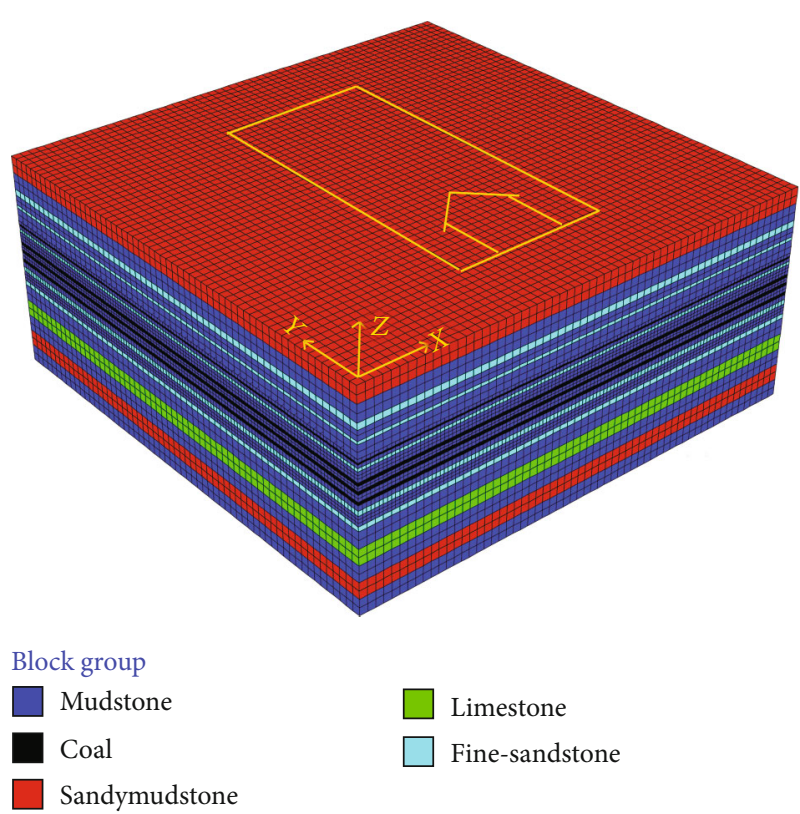

FIGURE 2: Numerical calculation model.

was $200 \mathrm{~m}$, which extends from 50 to $250 \mathrm{~m}$ along the $y$ -direction. Moreover, the mining width was $100 \mathrm{~m}$, which extends from 100 to $200 \mathrm{~m}$ along the $x$-direction, and the mining height was $1 \mathrm{~m}$. The model contained 349,200 grids and 400,243 zones (as shown in Figure 2).

2.3. Strain Data Extraction Method. Under the influence of the mining stress, a protected coal seam will be compressed or expand in three directions (the vertical, mining, and tilt directions). In other words, the deformation is mainly reflected in the change of the coal seam volume. The 
TABLE 2: Mechanical parameters of coal and rock.

\begin{tabular}{|c|c|c|c|c|c|c|c|}
\hline Lithology & Density $/ \mathrm{kg} / \mathrm{m}^{3}$ & $\begin{array}{c}\text { Bulk } \\
\text { modulus/GPa }\end{array}$ & $\begin{array}{c}\text { Shear } \\
\text { modulus/GPa }\end{array}$ & $\begin{array}{l}\text { Friction } \\
\text { angle }^{\circ}\end{array}$ & Cohesion/MPa & $\begin{array}{l}\text { Dilatancy } \\
\text { angle } /^{\circ}\end{array}$ & $\begin{array}{l}\text { Uniaxial tensile } \\
\text { strength/MPa }\end{array}$ \\
\hline $\begin{array}{l}\text { Sandy } \\
\text { mudstone }\end{array}$ & 2740 & 3.7 & 3.1 & 35 & 2.6 & 10 & 2.4 \\
\hline Mudstone & 2690 & 2.0 & 1.5 & 31 & 1.5 & 10 & 1.0 \\
\hline $\begin{array}{l}\text { Fine } \\
\text { sandstone }\end{array}$ & 2740 & 3.5 & 2.2 & 30 & 2.0 & 10 & 2.0 \\
\hline Coal & 1450 & 1.0 & 0.8 & 20 & 0.6 & 10 & 0.5 \\
\hline Limestone & 3080 & 3.9 & 3.5 & 43 & 4.8 & 10 & 3.2 \\
\hline
\end{tabular}

volumetric strain of a coal seam is equal to the sum of its strains in the three directions, and the extraction method of the strain data is presented as follows.

The strain in the $z$-direction (vertical direction) is

$$
\eta_{\mathrm{z}}=\frac{\mathrm{d}_{\text {floor }}-\mathrm{d}_{\text {roof }}}{\mathrm{m}}
$$

where $\eta_{\mathrm{z}}$ is the strain of the protected coal seam in the $z$ -direction, $\mathrm{d}_{\text {floor }}$ is the vertical displacement of the coal seam floor, $\mathrm{d}_{\text {roof }}$ is the vertical displacement of the coal seam roof, and $\mathrm{m}$ is the initial thickness of the coal seam.

The length and width of the grids in the \#2 coal seam were both $2.5 \mathrm{~m}$. When extracting the vertical strain, the vertical displacement of the grid boundary line between $2 \leq$ $x \leq 3$ along the coal seam floor was extracted first. The distance was then increased by $10 \mathrm{~m}$ along the $x$-direction, and the vertical displacement of the grid boundary line between $12 \leq x \leq 13$ was extracted. By analogy, a vertical displacement matrix of the coal seam floor with 120 rows $\times 30$ columns was obtained. Via the same method, the vertical displacement matrix of the coal seam roof was also obtained. According to Eq. (1), the vertical strain matrix of the \#2 coal seam was calculated.

The strain in the $x$-direction (tilt direction) is

$$
\eta_{\mathrm{x}}=\frac{\mathrm{d}_{\mathrm{xi}}-\mathrm{d}_{\mathrm{xj}}}{\mathrm{l}_{\mathrm{xi}-\mathrm{xj}}},
$$

where $\eta_{\mathrm{x}}$ is the strain of the protected coal seam in the $x$ -direction, $\mathrm{d}_{\mathrm{xi}}$ is the displacement of the coal seam in the $x$ -direction at position $\mathrm{xi}, \mathrm{d}_{\mathrm{xj}}$ is the displacement of the coal seam in the $x$-direction at position $\mathrm{xj}$, and $1_{\mathrm{xi} \sim \mathrm{xj}}$ is the initial width from xi to $x j$.

When extracting the strain in the $x$-direction, the displacement in the $x$-direction of the grid boundary line between $2 \leq x \leq 3$ was first obtained, which corresponds to the displacement $d_{x i}$. Then, the displacement of the grid boundary line between $4.5 \leq x \leq 5.5$ was obtained, which corresponds to the displacement $\mathrm{d}_{\mathrm{xj}}$. The initial width $(2.5 \mathrm{~m})$ between the two grid boundary lines corresponds to the $1_{\mathrm{xi}-\mathrm{xj}}$. According to Eq. (2), the $x$-direction strain between the two grid boundary lines can be calculated. The distance was then increased by $10 \mathrm{~m}$ along the $x$-direction, and the strain of the grid boundary lines between $12 \leq x \leq 13$ and that between $14.5 \leq x \leq 15.5$ were obtained. By analogy, a strain matrix of the coal seam in the $x$-direction with 120 rows $\times$ 30 columns was obtained.

The strain in the $y$-direction (mining direction) is

$$
\eta_{\mathrm{y}}=\frac{d_{\mathrm{yi}}-\mathrm{d}_{\mathrm{yj}}}{1_{\mathrm{yi} \sim \mathrm{yj}}},
$$

where $\eta_{\mathrm{y}}$ is the strain of the protected coal seam in the $y$ -direction, $\mathrm{d}_{\mathrm{yi}}$ is the displacement of the coal seam in the $y$-direction at position $\mathrm{yi}, \mathrm{d}_{\mathrm{yj}}$ is the displacement of the coal seam in the $y$-direction at position $y j$, and $1_{y i \sim y j}$ is the initial length from yi to yj.

The grid boundary line between $2 \leq x \leq 3$ was first determined, after which the displacements in the $y$-direction of the grids along the grid boundary line were extracted. For any grid, the side with a smaller $y$-coordinate corresponds to $d_{\mathrm{yi}}$ , the side with a larger $y$-coordinate corresponds to $\mathrm{d}_{\mathrm{yj}}$, and the initial length of the grid corresponds to $l_{y i \sim y j}$. The strain of each grid can be calculated by substituting the extracted data into Eq. (3). The distance was then increased by $10 \mathrm{~m}$ along the $x$-direction, and the strains of the grids along the grid boundary line between $12 \leq x \leq 13$ were obtained by the same method. By analogy, a strain matrix of the coal seam in the $y$-direction with 120 rows $\times 30$ columns was obtained.

The volumetric strain matrix of the protected coal seam can be obtained by directly adding the elements of the three strain matrices. The calculation formula is as follows:

$$
\eta_{\mathrm{v}}=\eta_{\mathrm{x}}+\eta_{\mathrm{y}}+\eta_{\mathrm{z}}
$$

where $\eta_{\mathrm{v}}$ is the volumetric strain of the protected coal seam.

\section{Strain Distribution of the Protected Coal Seam}

According to the method discussed in the previous section, the strain data of the protected coal seam were extracted. The data were processed by using the "surf" function and "meshgrid" command in MATLAB software, and the strain distributions were obtained. Figures 3-7 present the strain distribution diagrams of the protected coal seam when the working face of the protective coal seam was mined to different distances. In the figures, positive values of strain indicate 


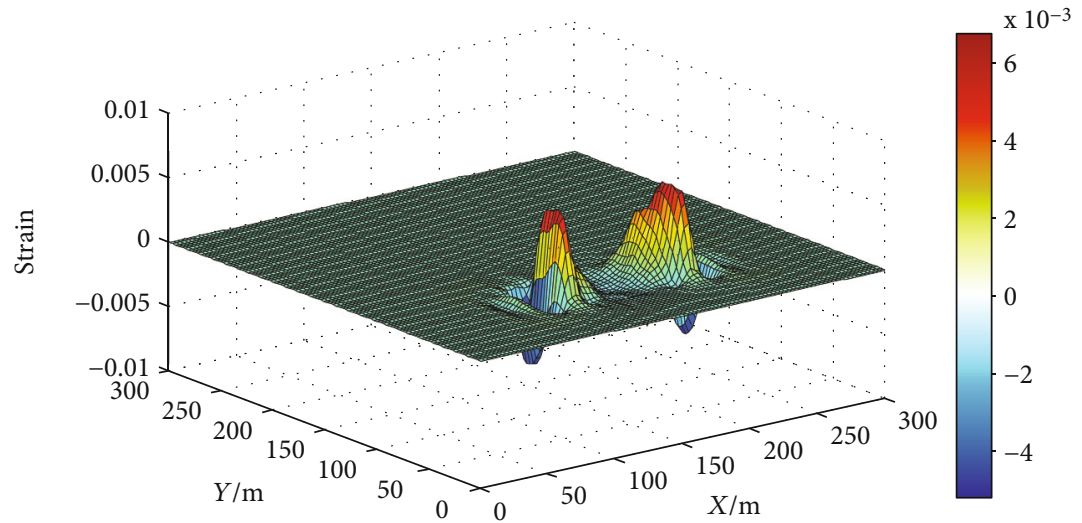

(a) Mined $50 \mathrm{~m}$

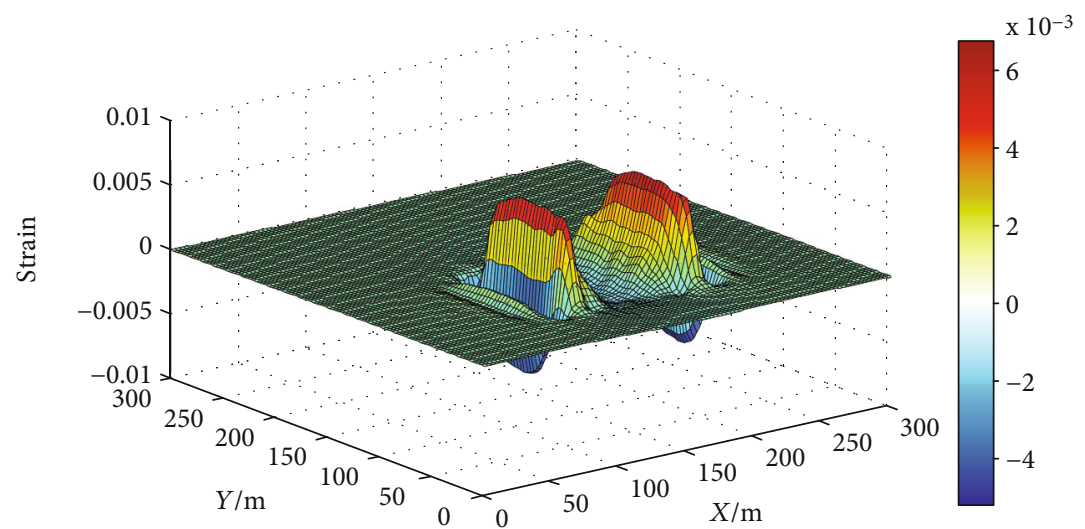

(b) Mined $100 \mathrm{~m}$

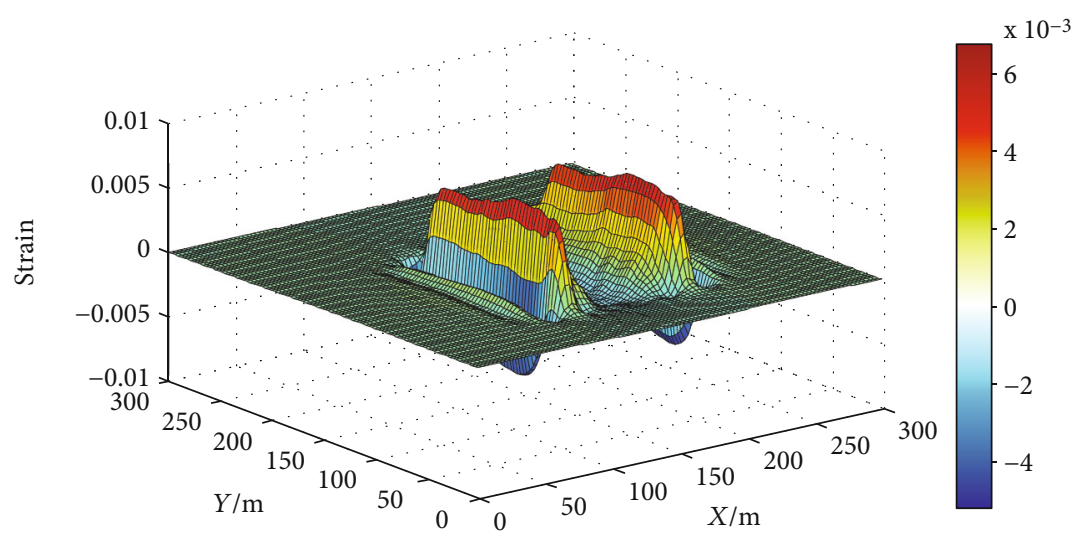

(c) Mined $150 \mathrm{~m}$

FIgURe 3: Continued. 


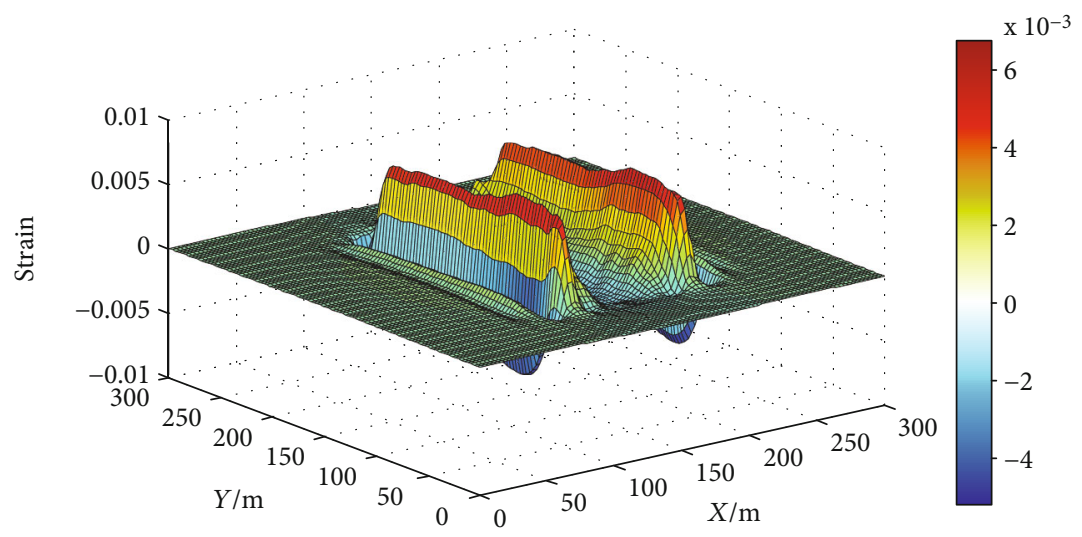

(d) Mined $200 \mathrm{~m}$

FIGURE 3: $X$-direction strain of protected coal seam.

that the coal seam underwent compression, while negative values indicate that the coal seam underwent expansion.

Figure 3 presents the $x$-direction strain of the protected coal seam, which was found to be mainly distributed near the coal pillars on both sides and inside the goaf, while the strain at the working face and the initial mining line was not obvious. The coal seam directly below the coal pillars was in a stress concentration zone, and the significantly increased vertical stress compressed the coal seam in the vertical direction and elongated it in the $x$-direction. The coal seam at the inner side of the coal pillars was located in a pressure relief zone, in which the vertical stress decreased the most and the coal seam was compressed in the $x$-direction under the increased horizontal deviatoric stress.

Figure 4 presents the $y$-direction strain of the protected coal seam, which was found to be mainly distributed at the working face, the initial mining line, and inside the goaf. The strain near the coal pillars on both sides was not obvious. The coal seam directly below the working face was found to expand in the $y$-direction, which was due to the vertical stress concentration in this area. The coal seam at the inner side of the initial mining line was compressed in the $y$-direction significantly; it was located in a pressure relief zone, and the degree of unloading of vertical stress in this zone was greater than that of horizontal stress. After the protective coal seam was mined, the floor strata tended to move to the goaf and stop in this zone. Under the dual action of the floor strata movement and vertical stress unloading, the coal seam in this zone was compressed in the $y$-direction.

Figure 5 exhibits the $z$-direction strain of the protected coal seam, which was found to be distributed at the working face, the initial mining line, the coal pillars on both sides, and inside the goaf. The coal seam directly below the working face, the initial mining line, and the coal pillars was compressed along the $z$-direction, whereas the coal seam in the goaf expanded significantly. In the goaf, the vertical strain was greater than the horizontal strain, which was determined by vertical stress unloading. With the advance of the working face, the stress in the central area of the goaf was gradually restored, and the degree of expansion of the coal seam exhibited a decreasing trend.
Figure 6 displays the volumetric strain of the protected coal seam. The distribution characteristics and the value of volumetric strain were found to be basically consistent with those of the $z$-direction strain. With the exploitation of the protective coal seam, the scope of the goaf expanded, and the volumetric strain presented an inverted saddle shape. To further investigate the distribution characteristics of the volumetric strain, the main view is shown in Figure 7 . It can be seen from the figure that the volumetric strain experienced the stages of increasing, decreasing, and then increasing again from the boundary to the interior of the model. The volumetric strain reached the maximum value in the stress concentration zone and decreased to the minimum value near the working face. The turning point of volumetric strain from increasing to decreasing was found to be about $15 \mathrm{~m}$ in front of the working face, which indicates that this was the starting point of the protected coal seam changing from elastic compression to damage expansion.

\section{Field Observation of the Gas Drainage Effect of the Protected Coal Seam}

The changes in the permeability and volumetric strain of protected coal seam both reflect the degree of pressure relief of the coal seam; thus, the permeability and volumetric strain have internal unity. Assuming that the gas pressure of the protected coal seam remains constant during protective coal seam mining, the gas drainage quantity of the coal seam is proportional to the permeability. Therefore, the change law of the gas drainage quantity can be used to verify the correctness of the distribution characteristics of the volumetric strain.

Two gas boreholes were preconstructed in the transportation roadway of the protected coal seam prior to the mining of the protective coal seam. The boreholes were arranged along the coal seam inclination direction and were used to measure the gas drainage quantity and gas drainage concentration with the advance of the working face (as shown in Figure 1). The initial horizontal distances between boreholes $\# 1$ and \#2 and the working face were 120 and $144 \mathrm{~m}$, respectively. The length of the boreholes was $120 \mathrm{~m}$, and the diameter was $94 \mathrm{~mm}$. 


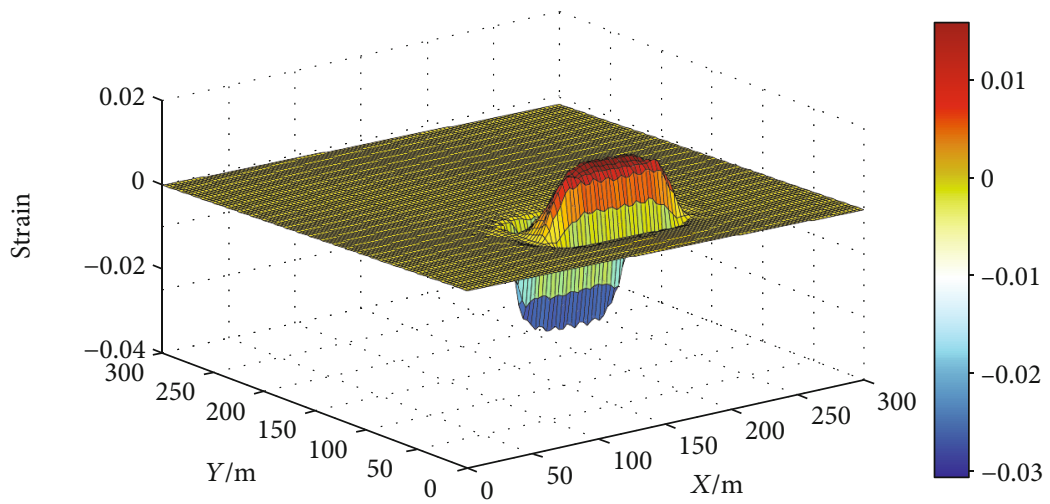

(a) Mined $50 \mathrm{~m}$

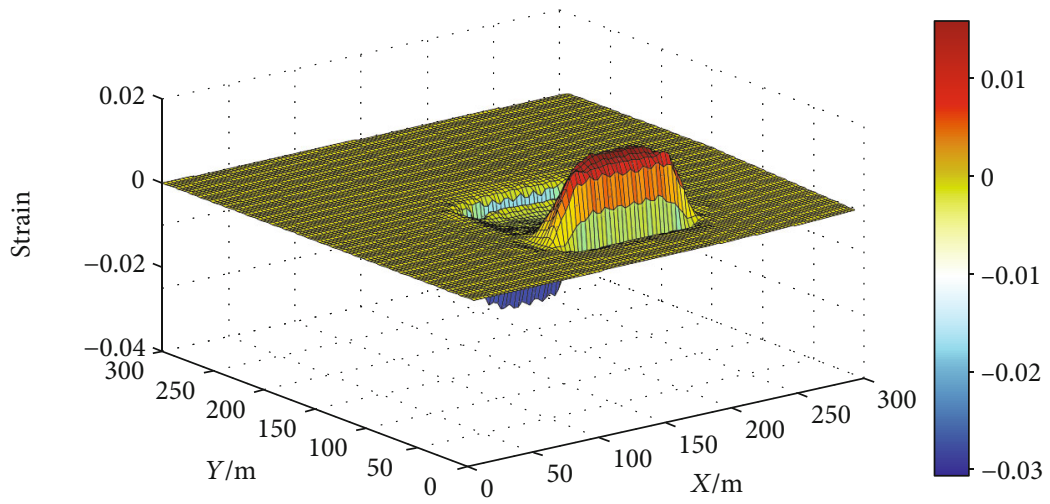

(b) Mined $100 \mathrm{~m}$

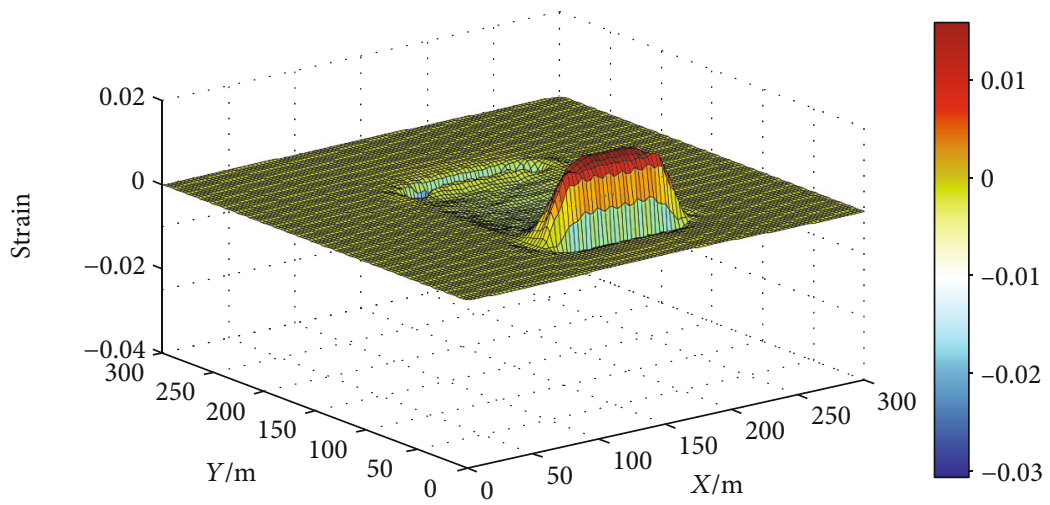

(c) Mined $150 \mathrm{~m}$

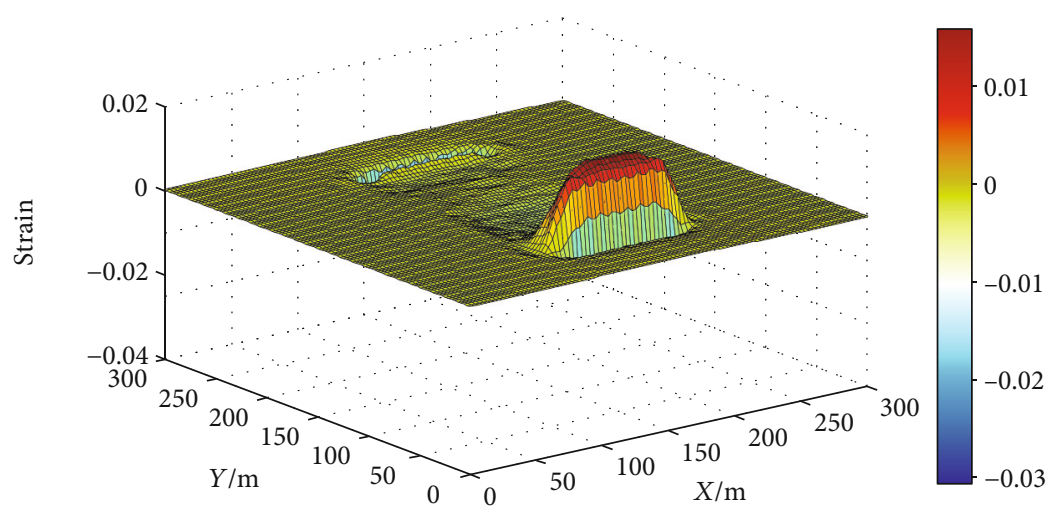

(d) Mined $200 \mathrm{~m}$

FIGURE 4: $Y$-direction strain of protected coal seam. 


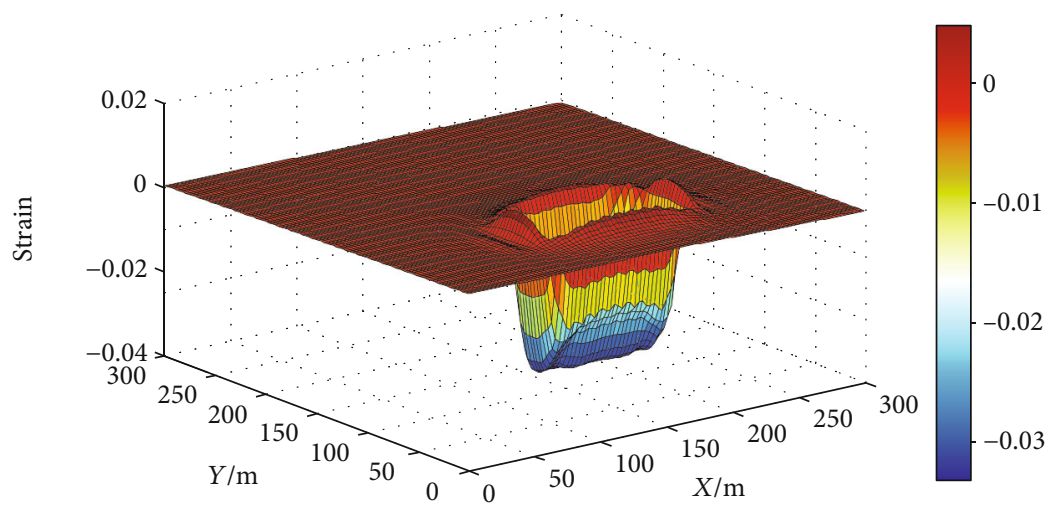

(a) Mined $50 \mathrm{~m}$

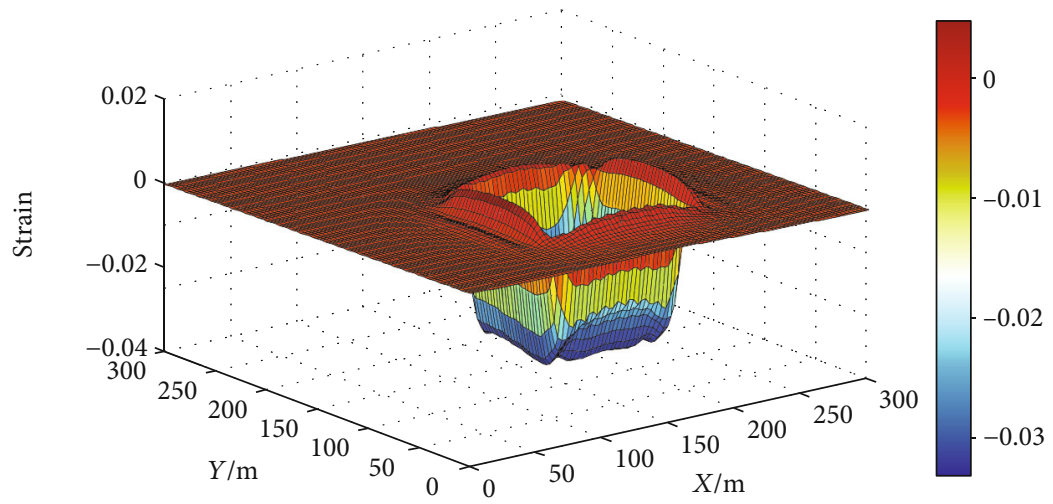

(b) Mined $100 \mathrm{~m}$

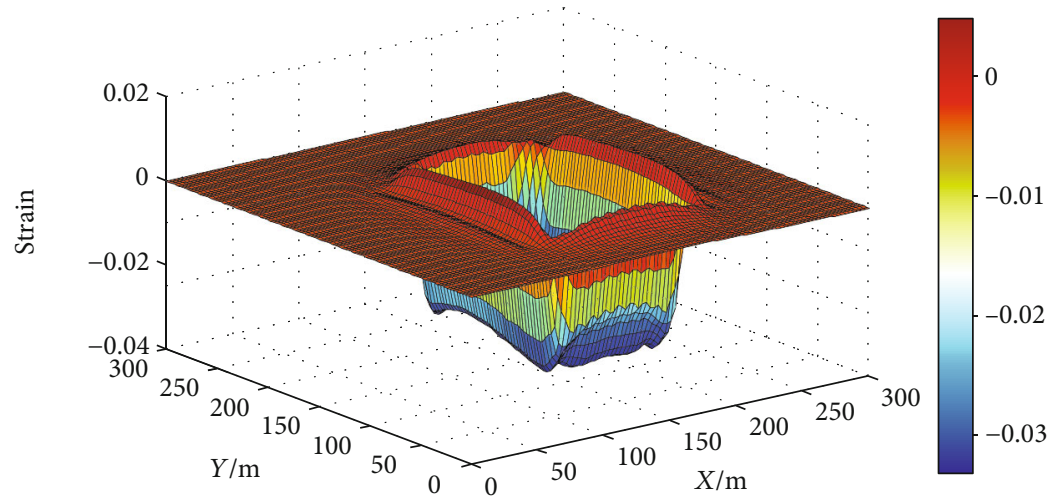

(c) Mined $150 \mathrm{~m}$

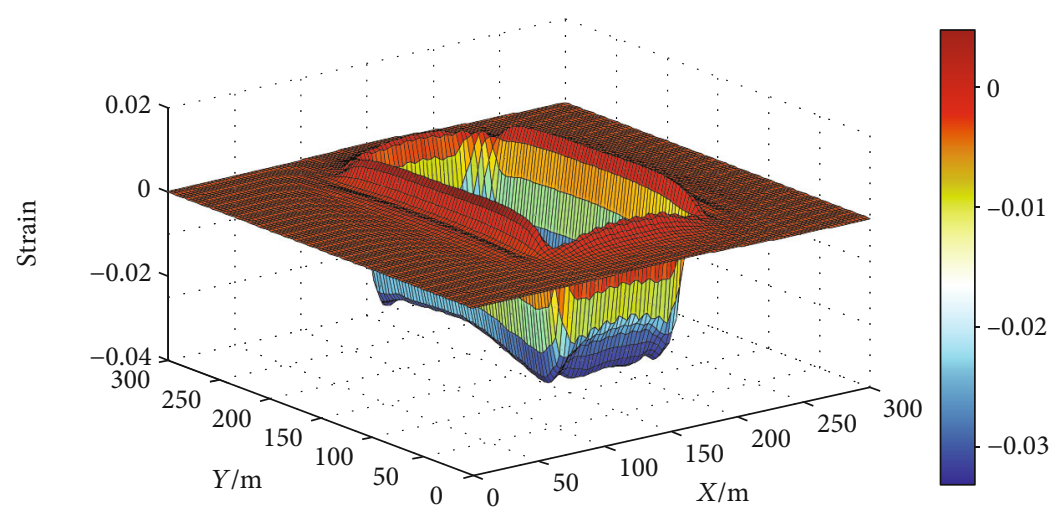

(d) Mined $200 \mathrm{~m}$

Figure 5: $Z$-direction strain of protected coal seam. 


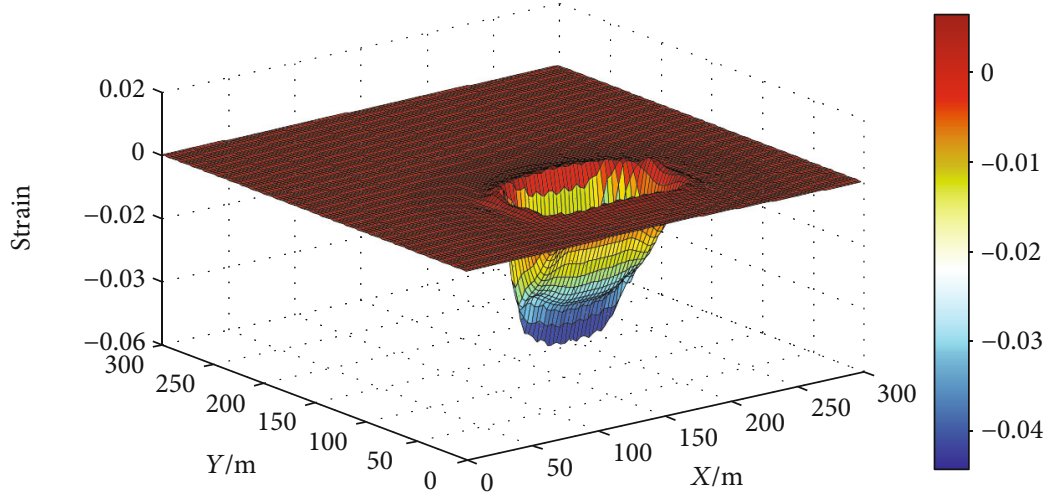

(a) Mined $50 \mathrm{~m}$

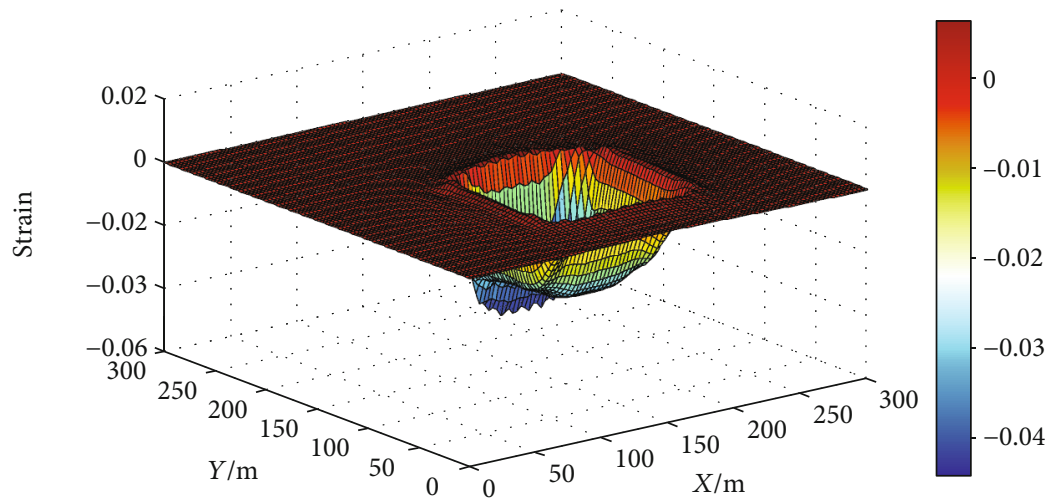

(b) Mined $100 \mathrm{~m}$

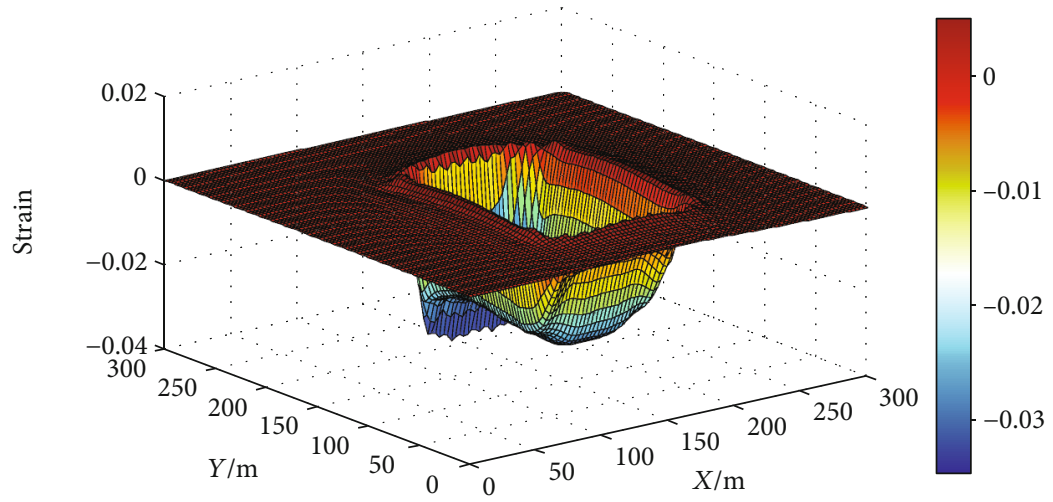

(c) Mined $150 \mathrm{~m}$

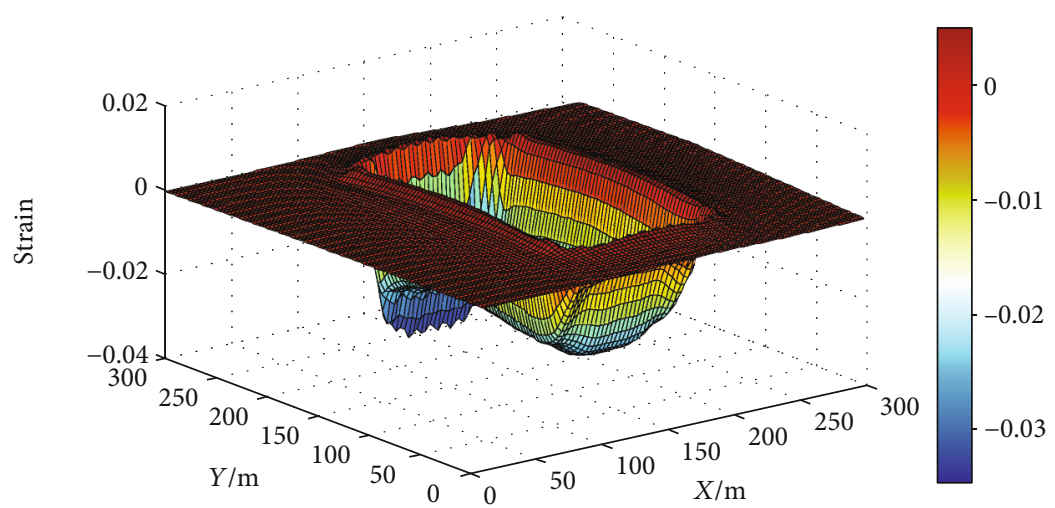

(d) Mined $200 \mathrm{~m}$

Figure 6: Volumetric strain of protected coal seam. 


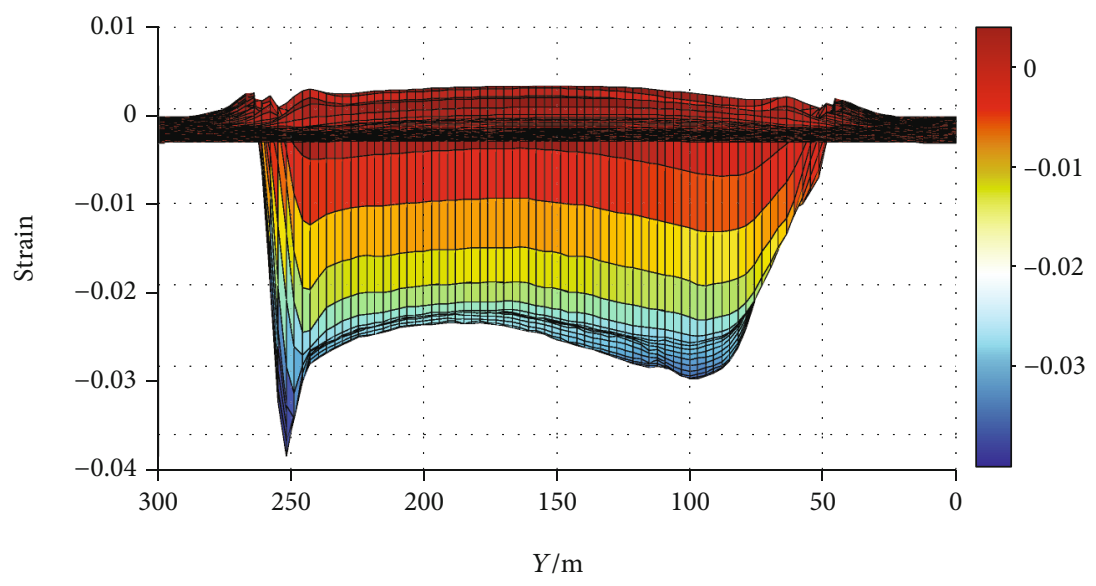

FIgURE 7: The main view of the volumetric strain.

Figure 8 presents the variation laws of the gas drainage quantity and gas concentration of the boreholes. The abscissa in the figure indicates the relative position between the boreholes and the working face. For example, $x=100$ means that the borehole was located $100 \mathrm{~m}$ in front of the working face, and $x=-50$ means that the borehole was located $50 \mathrm{~m}$ behind the working face. It can be seen from the figure that the mixed gas drainage quantity was relatively high at the initial stage of mining and decreased in a fluctuating manner with the advance of the working face. From about $15 \mathrm{~m}$ in front of the working face, the mixed gas drainage quantity, the pure gas drainage quantity, and the gas concentration began to increase rapidly. When the boreholes entered the goaf, these gas drainage values reached the maximum and remained stable for a period of time, after which they ultimately fluctuated inside the goaf. The variation laws of the gas drainage quantity and the gas concentration were found to be closely related to the distribution characteristics of the volumetric strain; the turning point of the rapid increase of gas drainage coincided with the starting point of damage expansion. These results prove the correctness of the distribution characteristics of the volumetric strain.

\section{Discussion}

Based on a numerical simulation, a method for the extraction of the strain data of a protected coal seam was proposed, and the strain distribution characteristics were obtained. The $x$ -direction strain was found to be mainly distributed near the coal pillars on both sides and inside the goaf, while the $y$-direction strain was found to be mainly distributed at the working face, the initial mining line, and inside the goaf. The deformation of the coal seam was affected by the change of stress and the deformable conditions, both of which caused the distribution difference of the horizontal strains. A stress concentration zone was formed around the stope, at which the significantly increased vertical stress caused the compression of the coal seam along the $z$-direction. The stress inside the goaf was greatly unloaded in all directions, and the coal seam swelled. The simulation results show that the distribution characteristics and the value of the volumet- ric strain were basically consistent with the $z$-direction strain, indicating that the $z$-direction strain has a decisive influence on the volumetric strain. Due to the restrictions of field measurement conditions and technology, scholars have often used vertical strain ( $z$-direction strain in this paper) to express the pressure relief effect of protected coal seams; although this operation is not perfect in theory, it is acceptable in fact.

With the advance of the working face, the protected coal seam entered the stress concentration zone from the original stress zone, and the coal seam experienced compression and damage expansion in turn. The turning point from compression to damage expansion was found to be about $15 \mathrm{~m}$ in front of the working face. With the further advance of the working face, the protected coal seam expanded rapidly after entering the goaf and then remained stable. Based on the results of gas drainage, it was determined that the mixed gas drainage quantity was higher in the initial stage and then gradually decreased with the advance of the working face, which was caused by the compression of the coal seam. The mixed gas drainage quantity, pure gas drainage quantity, and gas concentration began to increase rapidly at $15 \mathrm{~m}$ in front of the working face and then remained stable after entering the goaf. The variation law of gas drainage data was found to be closely related to the distribution characteristics of the volumetric strain, which proves the correctness of the numerical simulation results. Thus, it is feasible to verify the distribution characteristics of the volumetric strain of a protected coal seam via the gas drainage quantity and gas concentration in the boreholes.

The volumetric strain of a protected coal seam reveals only the degree of pressure relief of the coal seam and does not reveal the degree of permeability increase. If an evolution model of coal permeability with volumetric strain as a variable is established, and if the model is combined with coal seam volumetric strain, the distribution characteristics of permeability can be obtained. Xie et al. [19] considered the volumetric change of damaged coal with cracks induced by the coupling of the abutment pressure under different mining conditions, pore pressure, and expansion caused by gas adsorption, and proposed a new term for mining-enhanced permeability that reflects the change in permeability by the 

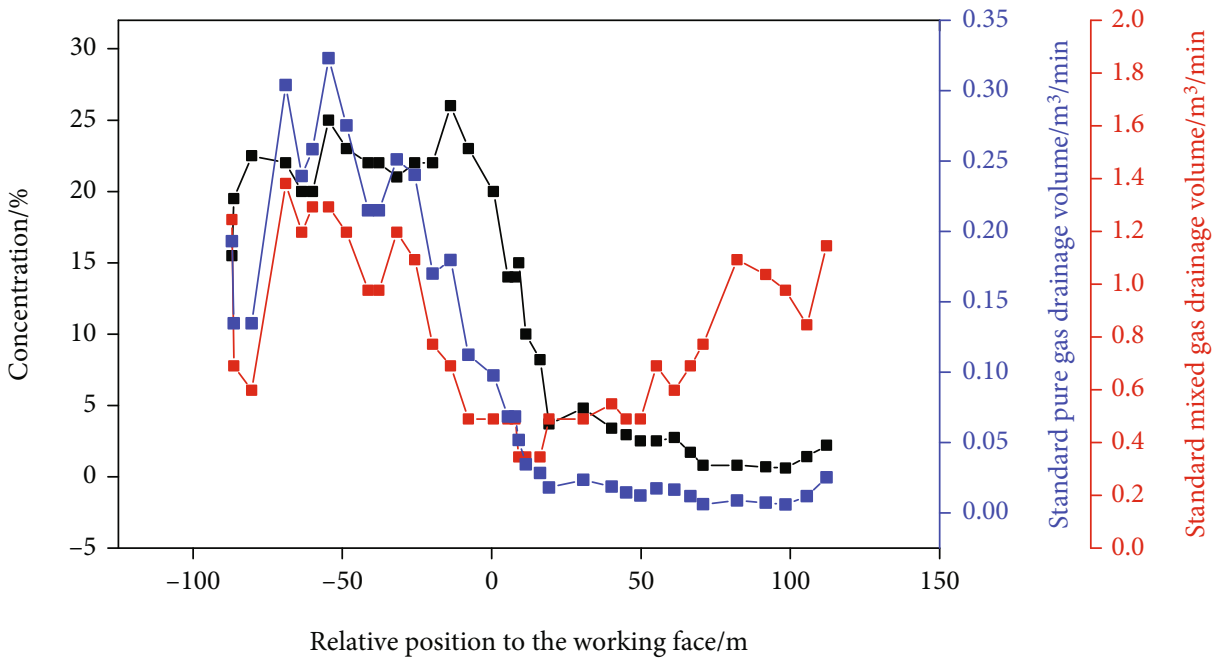

(a) \#1 borehole
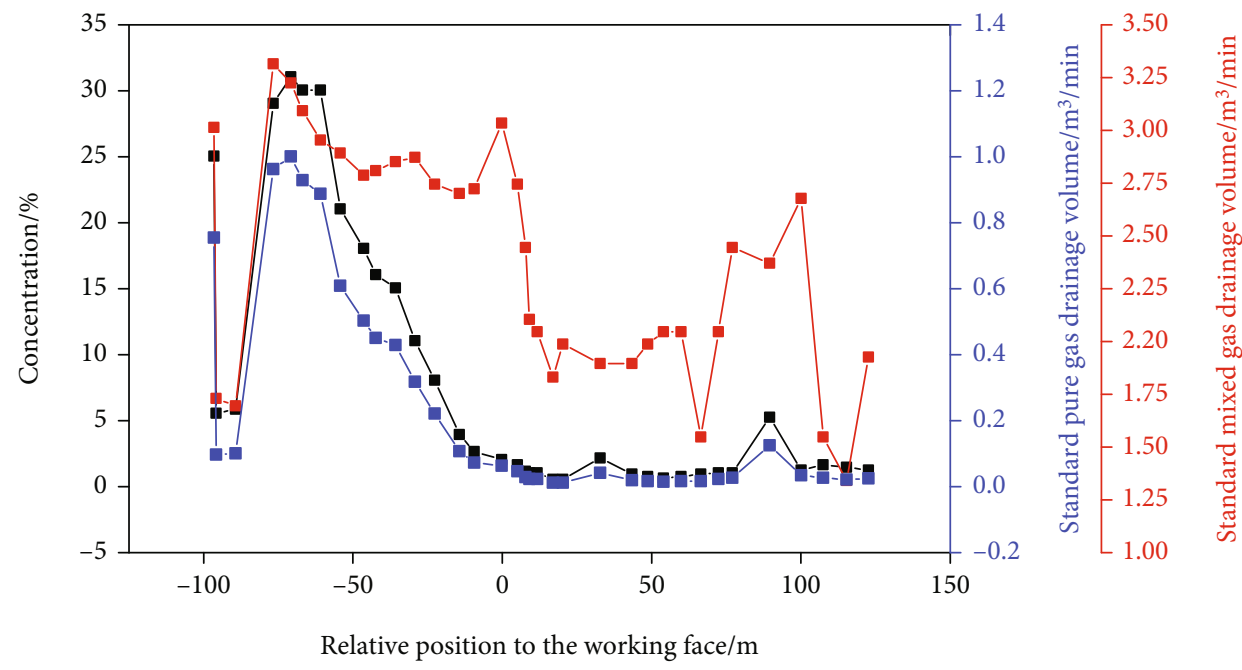

(b) \#2 borehole

FIGURE 8: Statistics of the gas drainage data [18].

volumetric change of coal. Cheng et al. [20] put forward a new model with strain as a variable for unloading fractured coal by considering the deformation effects of the effective stress and gas adsorption/desorption. These studies laid a theoretical foundation for obtaining the permeability enhancement effect of protected coal seams. However, there is a lack of research on the distribution characteristics of the volumetric strain of protected coal seams. Because coal and gas outburst accidents are becoming increasingly more serious [21-24], the present study both supplements and improves the previous research, and the results are of great significance to revealing the effect of the permeability enhancement of protected coal seams.

\section{Conclusion}

(1) The deformation of coal seams is affected by both the change in stress and the deformation conditions. The vertical strain of a coal seam dominates the change law and the value of volumetric strain.
Although it is not comprehensive to use the vertical strain to express the effect of pressure relief of protective coal seam mining in theory, it is acceptable in fact

(2) The change laws of the gas drainage quantity and gas concentration of a protected coal seam are closely related to the distribution characteristics of the volumetric strain. The turning point of the rapid increase of the gas drainage quantity and gas concentration coincides with the point of damage expansion. Thus, it is feasible to verify the distribution characteristics of the volumetric strain of a protected coal seam via the use of gas drainage data

(3) The volumetric strain only reveals the degree of pressure relief of a protected coal seam, but does not reveal the degree of permeability increase. The results of this study are of great significance for the comprehensive investigation of the effect of the permeability enhancement of protective coal seam mining 


\section{Data Availability}

The data used to support the findings of this study are available from the corresponding author upon request.

\section{Conflicts of Interest}

The author declares that there is no conflict of interest.

\section{Acknowledgments}

This research is financially supported by the National Natural Science Foundation of China (Grant no. 51704164).

\section{References}

[1] H. Wang, Z. Cheng, Q. Zou et al., "Elimination of coal and gas outburst risk of an outburst-prone coal seam using controllable liquid $\mathrm{CO}_{2}$ phase transition fracturing," Fuel (Guildford), vol. 284, article 119091, 2021.

[2] F. du, K. Wang, X. Zhang, C. Xin, L. Shu, and G. Wang, "Experimental study of coal-gas outburst: insights from coalrock structure, gas pressure and adsorptivity," Natural Resources Research, vol. 29, no. 4, pp. 2481-2493, 2020.

[3] M. B. Díaz Aguado and C. González Nicieza, "Control and prevention of gas outbursts in coal mines, Riosa-Olloniego coalfield, Spain," International Journal of Coal Geology, vol. 69, no. 4, pp. 253-266, 2007.

[4] E. Krause and J. Skiba, "Formation of methane hazard in longwall coal mines with increasingly higher production capacity," International Journal of Mining Science and Technology, vol. 24, no. 3, pp. 403-407, 2014.

[5] D. Guowei and Z. Yinhui, "A novel method for selecting protective seam against coal and gas outburst: a case study of Wangjiazhai coal mine in China," Sustainability, vol. 9, no. 6, p. 1015, 2017.

[6] J. Jiang, Y. Cheng, P. Zhang, K. Jin, J. Cui, and H. du, "CBM drainage engineering challenges and the technology of mining protective coal seam in the Dalong Mine, Tiefa Basin, China," Journal of Natural Gas Science and Engineering, vol. 24, pp. 412-424, 2015.

[7] F. du and K. Wang, "Unstable failure of gas-bearing coal-rock combination bodies: insights from physical experiments and numerical simulations," Process Safety and Environmental Protection, vol. 129, pp. 264-279, 2019.

[8] Q. Huang, S. Liu, W.-m. Cheng, and G. Wang, "Fracture permeability damage and recovery behaviors with fracturing fluid treatment of coal: an experimental study," Fuel, vol. 282, article 118809,2020

[9] Q. Huang, S. Liu, G. Wang, and W. Cheng, "Evaluating the changes of sorption and diffusion behaviors of Illinois coal with various water-based fracturing fluid treatments," Fuel, vol. 283, article 118884, 2021.

[10] M. Tu, X. X. Miao, and N. B. Huang, "Deformation rule of protected coal seam exploited by using the long-distance-lower protective seam method," Journal of Mining and Safety Engineering, vol. 23, no. 3, pp. 253-257, 2006.

[11] Z. Ma, M. Tu, J. MA, B. Zhang, and M. Han, "Rock mass deformation characteristics for coal mining at remote lower protective seam," Journal of Mining and Safety Engineering, vol. 25, no. 3, pp. 253-257, 2008.
[12] Z. Shujin, L. Shaoquan, and L. Shuqing, "Experimental study on swelling deformation law of mining seam in dual protective seam of seam group," Coal Engineering, vol. 45, no. 9, pp. 8790, 2013.

[13] D. Zhixu and L. Qiang, "Study on pressure unloading effect of lower coal seam under upper protective layer in a kilometer deep well," Safety in Coal Mines, vol. 50, no. 4, pp. 6-9, 2019.

[14] Z. H. Wang-lei, X. I. Zu-qiang, W. A. Hong-yan, and Z. H. Yao-hui, "Study on deformation law of overlying roadway under condition of lower protective seam mining," Coal Science and Technology, vol. 42, no. 5, pp. 9-12, 2014.

[15] S. H. I. Bi-ming and L. I. U. Ze-gong, "Numerical simulation of the upper coal and rock deformation characteristic caused by mining protecting stratum," Journal of China Coal Society, vol. 33 , no. 1 , pp. $17-22,2008$.

[16] H. Aiping, F. Hua, L. Yangbo, and H. Bingjie, "Analysis method on swelling deformation of protected seam in the process of protective coal seam exploitation," Journal of Safety Science and Technology, vol. 12, no. 8, pp. 60-67, 2016.

[17] W. Yang, B.-q. Lin, Y. A. Qu et al., "Mechanism of strata deformation under protective seam and its application for relieved methane control," International Journal of Coal Geology, vol. 85, no. 3-4, pp. 300-306, 2011.

[18] H. Jia, K. Wang, C. Xu, and Q. Fu, "Permeability distribution characteristics of underlying coal seam disturbed by mining activity," Energy Sources, Part A: Recovery, Utilization, and Environmental Effects, pp. 1-16, 2019.

[19] X. HP, Z. HW, C. GM, and Z. FB, "On theoretical and modeling approach to mining-enhanced permeability for simultaneous exploitation of coal and gas," Journal of China Coal Society, vol. 7, pp. 1101-1108, 2013.

[20] C. YP, L. HY, G. PK, P. RK, and W. LA, "A theoretical model and evolution characteristic of mining-enhanced permeability in deeper gassy coal seam," Journal of China Coal Society, vol. 8, pp. 1650-1658, 2014.

[21] K. Wang and F. Du, "Coal-gas compound dynamic disasters in China: a review," Process Safety and Environmental Protection, vol. 133, pp. 1-17, 2020.

[22] H. Wang, X. Yang, F. Du et al., "Calculation of the diffusion coefficient of gas diffusion in coal: the comparison of numerical model and traditional analytical model," Journal of Petroleum Science and Engineering, vol. 205, article 108931, 2021.

[23] V. Palchik, "Formation of fractured zones in overburden due to longwall mining," Environmental Geology, vol. 44, no. 1, pp. 28-38, 2003.

[24] C. Karacan, F. A. Ruiz, M. Cotè, and S. Phipps, "Coal mine methane: a review of capture and utilization practices with benefits to mining safety and to greenhouse gas reduction," International Journal of Coal Geology, vol. 86, no. 2-3, pp. 121-156, 2011. 